\title{
Large-Scale Synthesis of Silver Nanoparticles by Aqueous Reduction for Low-Temperature Sintering Bonding
}

\author{
Qiu Xiliang, ${ }^{1}$ Cao Yang, ${ }^{1}$ Lin Tiesong, ${ }^{1}$ He Peng, ${ }^{1}$ Wang Jun, ${ }^{1}$ Liu Ping, ${ }^{2}$ and Gu Xiaolong ${ }^{2}$ \\ ${ }^{1}$ State Key Laboratory of Advanced Welding and Joining, Harbin Institute of Technology, Harbin 150001, China \\ ${ }^{2}$ Zhejiang Province Key Laboratory of Soldering \& Brazing Materials and Technology, \\ Zhejiang Metallurgical Research Institute Co., Ltd., Hangzhou 310030, China
}

Correspondence should be addressed to He Peng; hithepeng@hit.edu.cn

Received 28 February 2014; Revised 6 May 2014; Accepted 6 May 2014; Published 21 May 2014

Academic Editor: Tong Zhang

Copyright (C) 2014 Qiu Xiliang et al. This is an open access article distributed under the Creative Commons Attribution License, which permits unrestricted use, distribution, and reproduction in any medium, provided the original work is properly cited.

\begin{abstract}
Silver nanoparticles with average diameter of $22.4 \mathrm{~nm}$ were prepared by aqueous reduction method for low-temperature sintering bonding application. The reaction temperature and PVP concentration, which are the influential factors of nanoparticle characteristics, were investigated during reduction process. In our research, monodispersity of nanoparticles was remarkably improved while unfavorable agglomeration was avoided with the $\mathrm{AgNO}_{3} / \mathrm{PVP}$ mass ratio of $1: 4$ at the reaction temperature $30^{\circ} \mathrm{C}$. Besides, copper pads were successfully bonded using sintering paste employing fresh silver nanoparticles with diameter of $20 \sim 35 \mathrm{~nm}$ at $200^{\circ} \mathrm{C}$. In addition, after morphology of the bonding joint was analysed by scanning electron microscope (SEM), the porous sintering characteristics were confirmed.
\end{abstract}

\section{Introduction}

With the increasing awareness to the environmental protection, lead containing materials which are quite widely applied as bonding material in electronic packaging technologies but are harmful to the environment and human body have been prohibited by many countries $[1,2]$. Accordingly, leadfree solder systems such as $\mathrm{Sn}-\mathrm{Cu}, \mathrm{Sn}-\mathrm{Ag}-\mathrm{Cu}$, and $\mathrm{Sn}-\mathrm{Bi}$ have been well studied in recent twenty years, but there are still some inevitable drawbacks which hinder the large-scale replacement of tin-lead solder in all areas. For instance, (i) the wettability of $\mathrm{Sn}-\mathrm{Cu}$ solder is poor, and it does not have an excellent matching soldering flux; (ii) $\mathrm{Sn}-\mathrm{Ag}$ - $\mathrm{Cu}$ solder has a high soldering temperature; it is also easy to have the tin whisker and metal compounds coarsening problem; (iii) Sn-Bi solder has the disadvantages such as brittleness, poor processing property, and bad electrical or thermal conductivity [3]. Therefore, other new lead-free bonding materials, which promise almost the same packaging temperature as tin-based solders without these disadvantages, are needed urgently. Meanwhile, in order to satisfy the electronic components' requirements for high-performance and highreliability because of the harsh operational environment [4], the mechanical and electrical performance of the joint should be good.

Silver nanoparticles, which are easily sintered together at low temperature, could be applied as an ideal lead-free alternative. The high surface energy reduces the connection temperature to $200 \sim 300^{\circ} \mathrm{C}$ and the high melting point $\left(960^{\circ} \mathrm{C}\right)$ of silver makes it possible for high-temperature packaging applications. Furthermore, the voids in the connectional silver layer throughout the joint decrease the elastic modulus, which enhance the reliability [5]. Currently, some researchers have already used silver nanoparticle sintering paste to connect $\mathrm{Cu}$ substrate coated $\mathrm{Ag} / \mathrm{Ni}, \mathrm{Ag}, \mathrm{Cu}$, or $\mathrm{Au} / \mathrm{Ni}$ with shear strength of 17 40 MPa [6-8].

Although there are a few reported researches about silver nanoparticles sintering paste, it still needs to be well improved for outstanding performance. The characteristics of silver nanoparticles such as morphology, dispersion, and diameter distribution significantly influence sintering process. Therefore, the preparation of silver nanoparticles with good dispersibility, uniform particle size, and without agglomeration is prerequisite for lead-free packaging applications.

In this paper, silver nanoparticles were prepared by aqueous reduction method, using $\mathrm{AgNO}_{3}, \mathrm{NaBH}_{4}$, and 


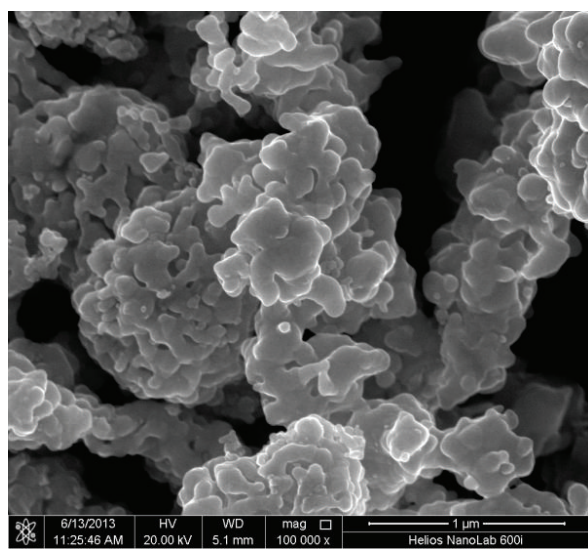

(a)

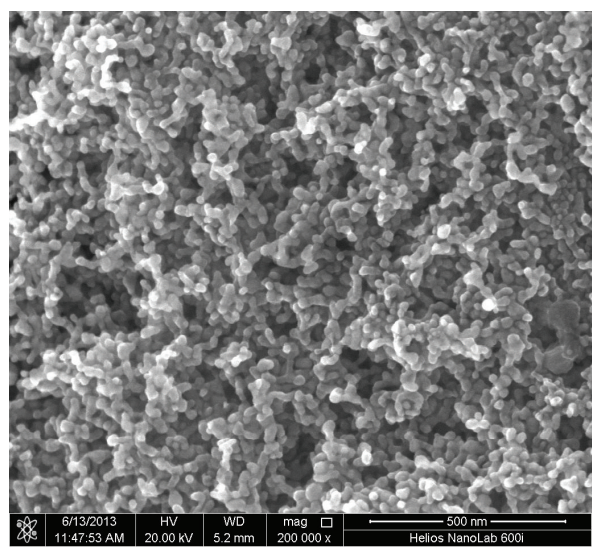

(c)

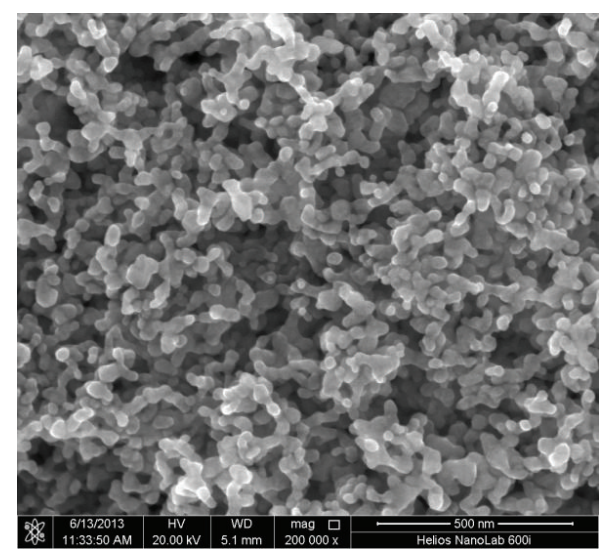

(b)

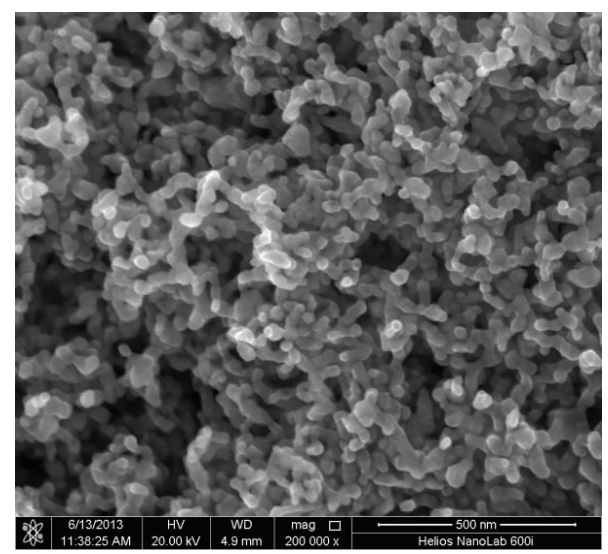

(d)

FIGURE 1: The SEM images of silver nanoparticles with different concentration of PVP: (a) $1: 0$; (b) $1: 2$; (c) $1: 4 ;$ (d) $1: 6$.

polyvinylpyrrolidone (PVP) as raw materials. After preparation, we explored the influence of PVP concentration and reaction temperature on particle size, morphology, and polymerization degree of the nanosilver.

\section{Experimental}

We used the nanosilver sintering paste which was prepared by nanoparticles to connect oxygen-free copper pad; then we observed and analyzed the microstructure and morphology of the sintering interface. Detailed steps are as follows. Firstly, $\mathrm{AgNO}_{3}$ was dissolved in deionized water with stirring. Secondly, PVP of different quality was, respectively, added into $\mathrm{AgNO}_{3}$ solution at room temperature to obtain oxidation liquid. At the same time, we put $\mathrm{NaBH}_{4}$ powder into $\mathrm{NaOH}$ solution in low concentration and stirred slowly to get colorless reducing solution. Thirdly, we mixed the oxidation liquid and reducing solution on the electric magnetic agitation apparatus with the instillment method at uniform speed of 30 drops per minute and at the constant temperature which was set beforehand. The stirring time was 30 minutes. Finally, we washed the silver nanoparticles colloid using centrifuge machine after aging to make it isolated and reduce the content of PVP. The concentration of raw material is shown in Table 1.
TABLE 1: The concentration of raw material.

\begin{tabular}{lccc}
\hline Raw material & $\mathrm{AgNO}_{3}$ & $\mathrm{NaBH}_{4}$ & $\mathrm{NaOH}$ \\
\hline $\begin{array}{l}\text { Concentration } \\
\text { mol/L } \times \mathrm{mL}\end{array}$ & $1 \times 10^{-2} \times 25$ & $1 \times 10^{-2} \times 75$ & $0.0125 \times 100$ \\
\hline
\end{tabular}

After preparation, the morphology of silver particles and statistics of the particle size were acquired by the use of scanning electron microscope (SEM) and software named Nano Measurer 1.2.

The copper substrate was cut into $6 \times 6 \mathrm{~mm}$ or $12 \times$ $12 \mathrm{~mm}$ squares, and the surface was pretreated. Firstly, we immersed it in $98 \%$ ethanol for ultrasonic for $10 \mathrm{~min}$, and after drying we soaked it in 5\% dilute hydrochloric acid for $5 \mathrm{~min}$ to remove surface oxide. Finally, we washed the sample with distilled water and made it dry. When we prepared the water-based sintering paste, sintering particles must be dispersed uniformly in aqueous solution containing PVP using ultrasonic device, and then polyethylene glycol was added gradually to increase system viscosity. The sintering paste composition is shown in Table 2. Besides, the sinter condition is $10 \mathrm{MPa}, 200^{\circ} \mathrm{C}$, and $30 \mathrm{~min}$. 


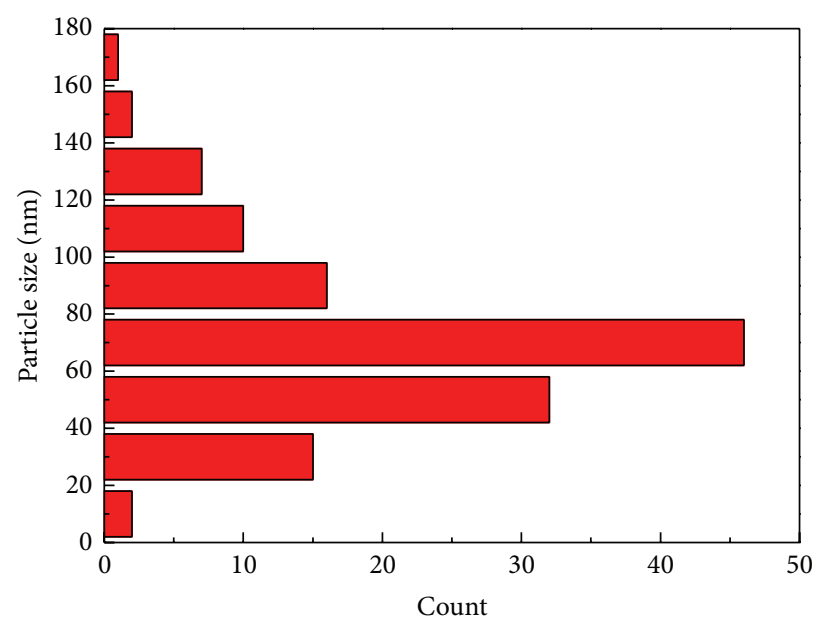

(a)

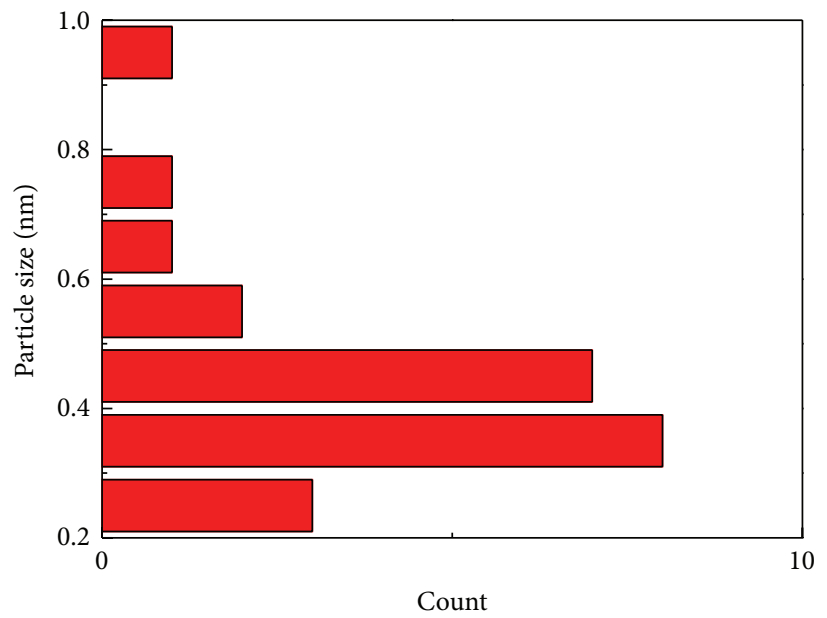

(c)

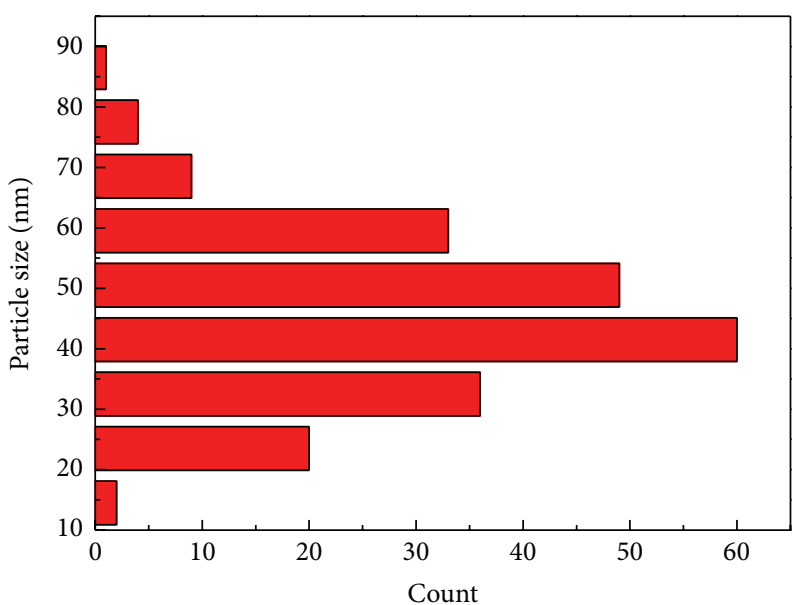

(b)

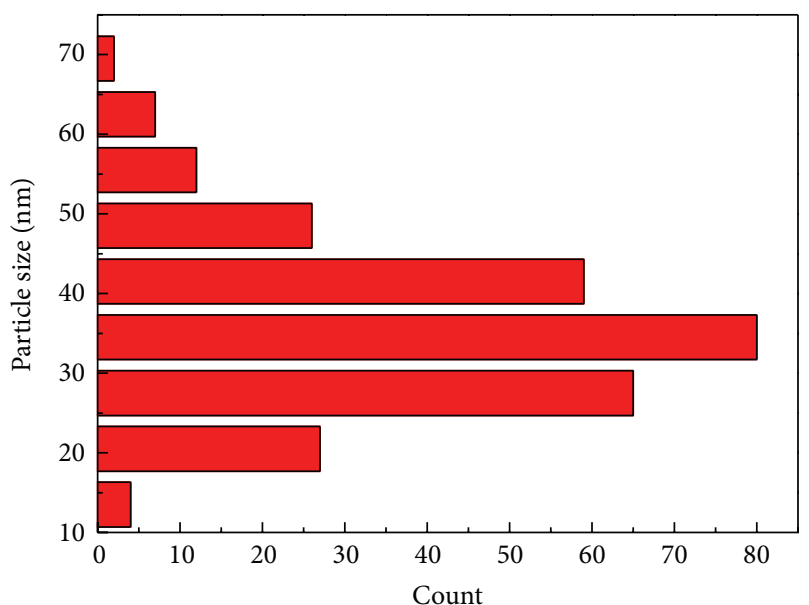

(d)

FIGURE 2: The particle diameter distribution range of silver nanoparticles with different concentrations of PVP: (a) $1: 0$; (b) $1: 2$; (c) $1: 4$; (d) $1: 6$.

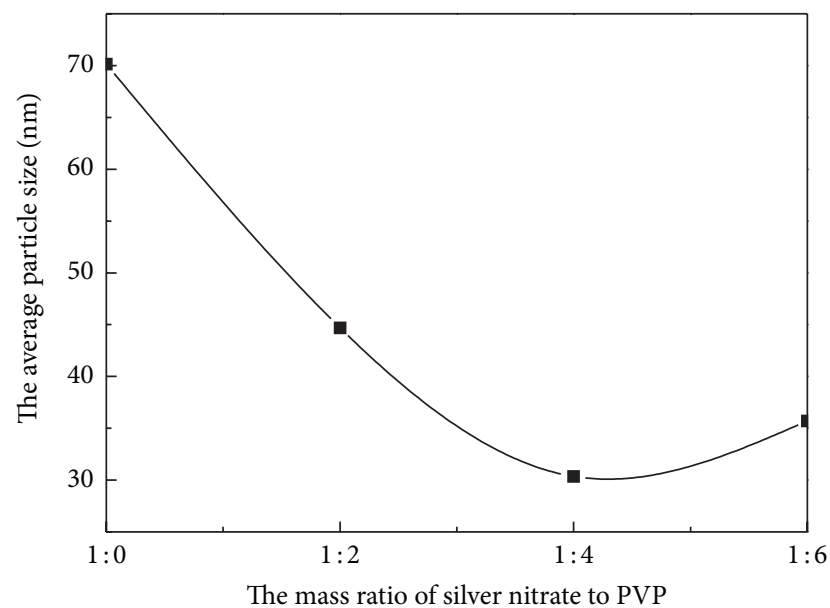

FIGURE 3: The relation of average silver nanoparticles particle diameter with the concentration of PVP.
TABLE 2: The component of soldering paste.

\begin{tabular}{lccc}
\hline Silver nanoparticles & Water & PVP & Polyethylene glycol \\
\hline $85.0 \%$ & $3.0 \%$ & $0.001 \%$ & $12.0 \%$
\end{tabular}

\section{Results and Discussion}

3.1. The Influence of PVP Concentration on Silver Nanoparticles. Silver nanoparticles were synthesized by aqueous reduction. Their scanning electron microscopy (SEM) images with the increasing concentration of PVP are shown in Figure 1 and the statistics of particle size are shown in Figure 2; besides, the curves of average silver nanoparticles size are shown in Figure 3. From Figure 1(a) and Figure 2(a), we observed the silver nanoparticles in various shapes and serious agglomeration phenomenon when the mass ratio of $\mathrm{AgNO}_{3}$ to PVP was 1:0, and the average particle size was 


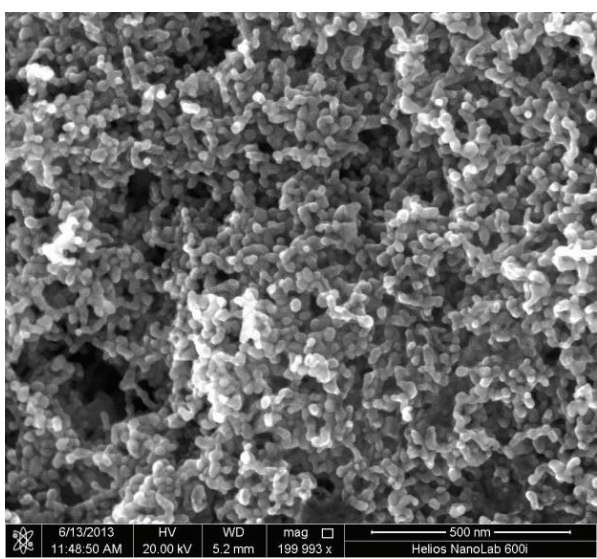

(a)

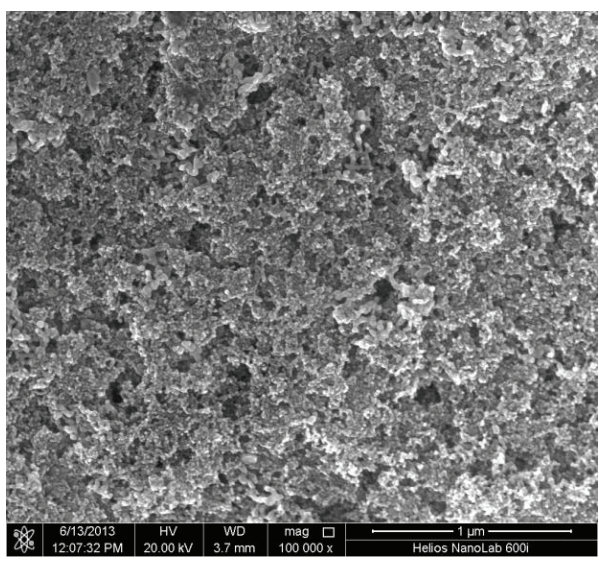

(c)

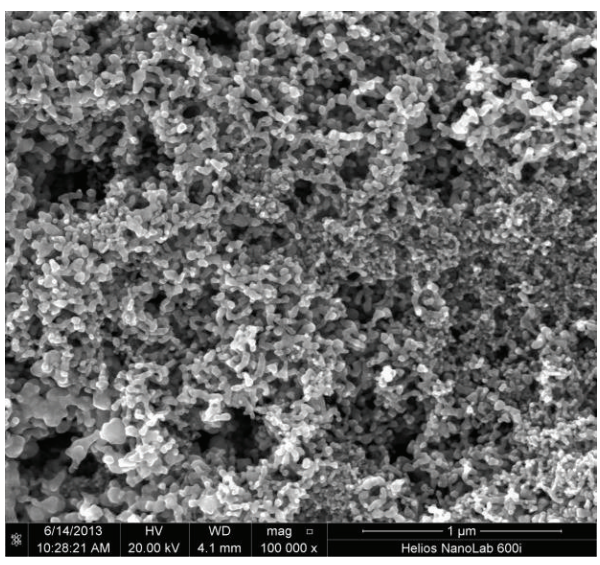

(e)

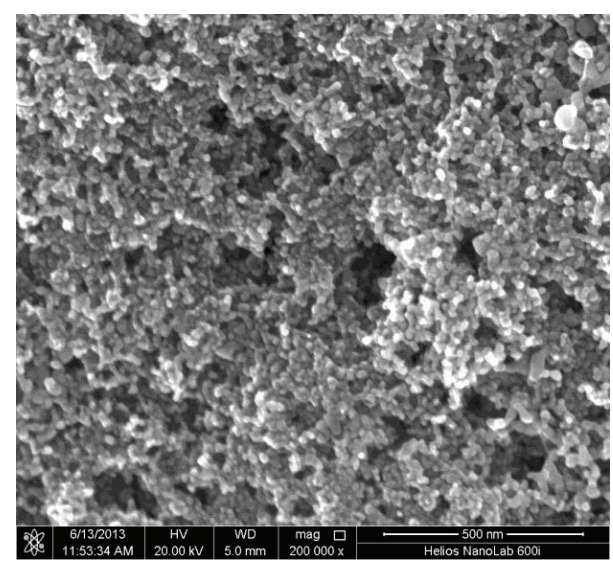

(b)

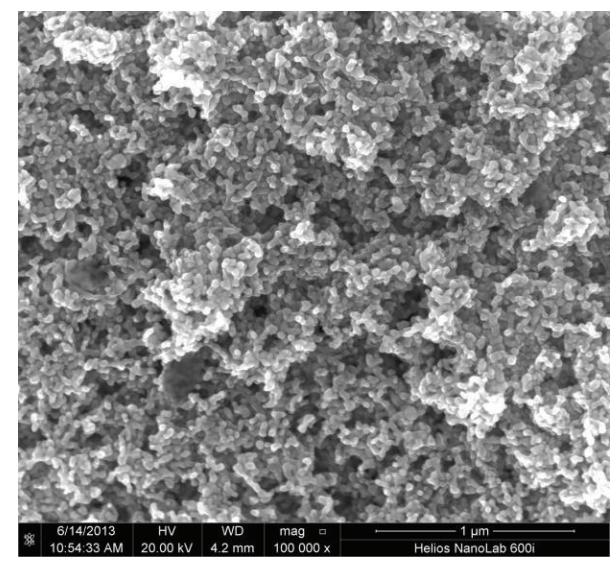

(d)

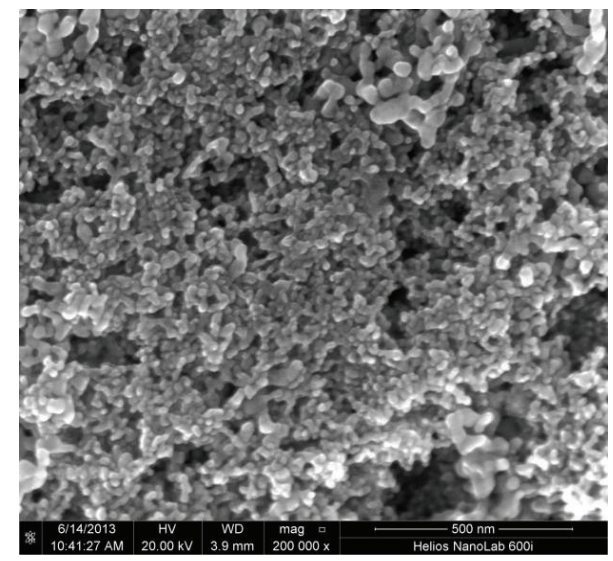

(f)

Figure 4: The SEM images of silver nanoparticles with different temperatures: (a) $5^{\circ} \mathrm{C}$; (b) $20^{\circ} \mathrm{C}$; (c) $30^{\circ} \mathrm{C}$; (d) $40^{\circ} \mathrm{C}$; (e) $55^{\circ} \mathrm{C}$; (f) $70^{\circ} \mathrm{C}$.

$70.1 \mathrm{~nm}$; when the mass ratio of $\mathrm{AgNO}_{3}$ to PVP comes to $1: 2$, the shape and agglomeration of the particles were significantly improved, and the average particle size was $44.7 \mathrm{~nm}$. When the mass ratio of $\mathrm{AgNO}_{3}$ to PVP was 1:4, most of nanoparticles were spherical ones with average diameter of $30.3 \mathrm{~nm}$, which dispersed well in the solution. When the mass ratio of $\mathrm{AgNO}_{3}$ to PVP is $1: 6$, the morphological regularity, dispersion, and agglomeration of the particles were deteriorated, and the average particle size was $35.7 \mathrm{~nm}$. As shown in Figure 3, particle size decreased at first and then increased accompanied with PVP concentration; meanwhile, the average particle size $(30.3 \mathrm{~nm})$ was the smallest when the mass ratio of $\mathrm{AgNO}_{3}$ to PVP was 1:4. PVP is applied as dispersant and adsorbed on the surface of silver nanoparticles formerly on the coordinate bond. This effect provides the space steric hindrance and stabilizes the colloid system [9, 10]. Therefore appropriate concentration of PVP can prevent the silver nanoparticles particles agglomeration, but if the 


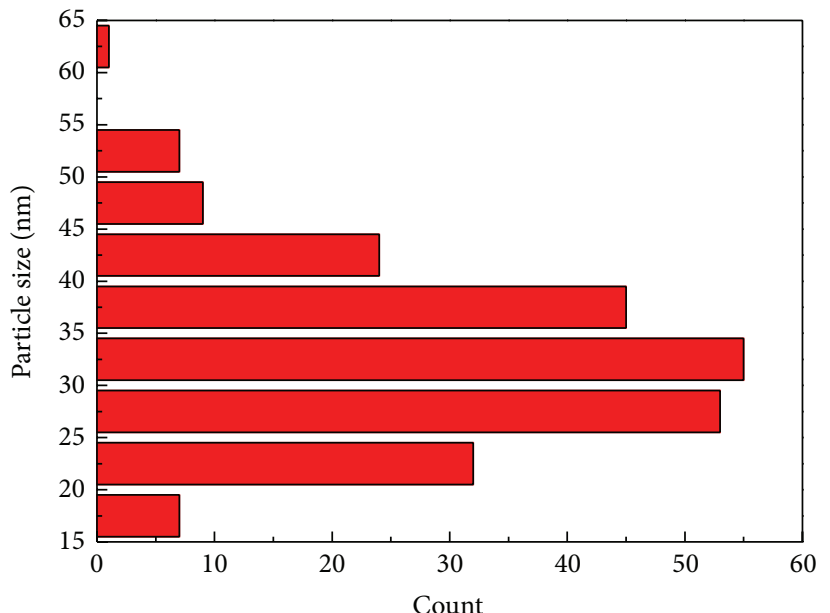

(a)

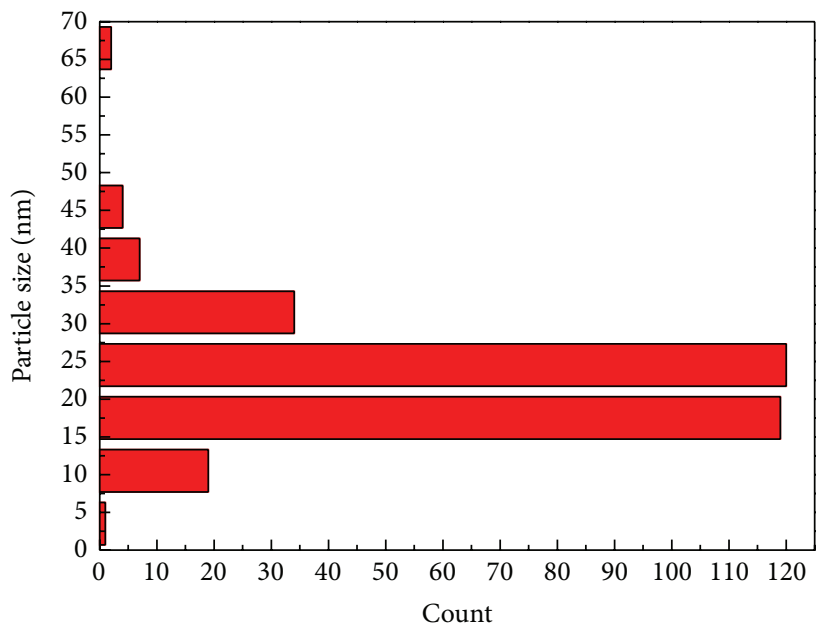

(c)

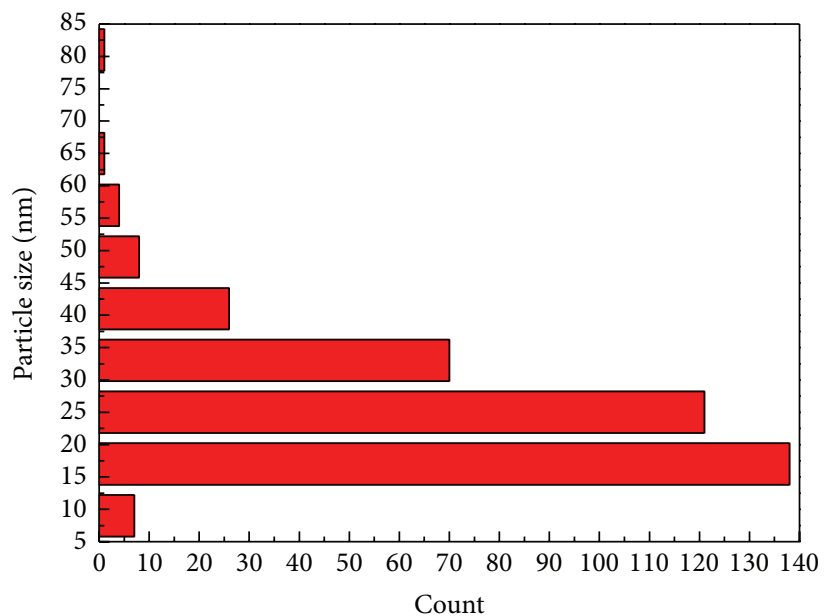

(e)

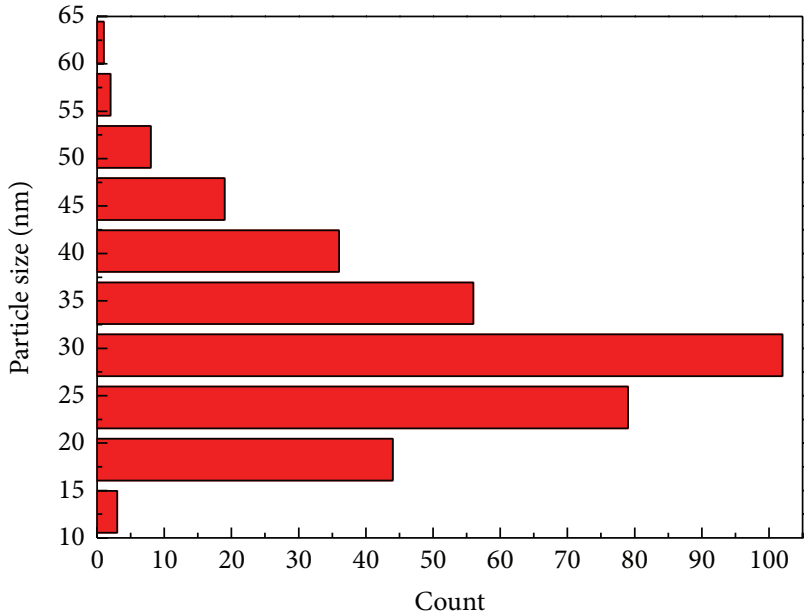

(b)

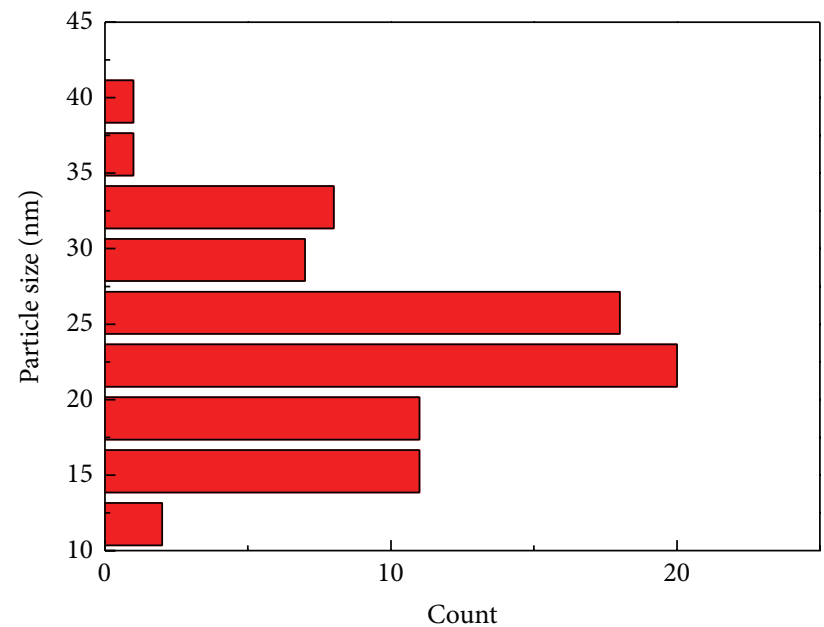

(d)

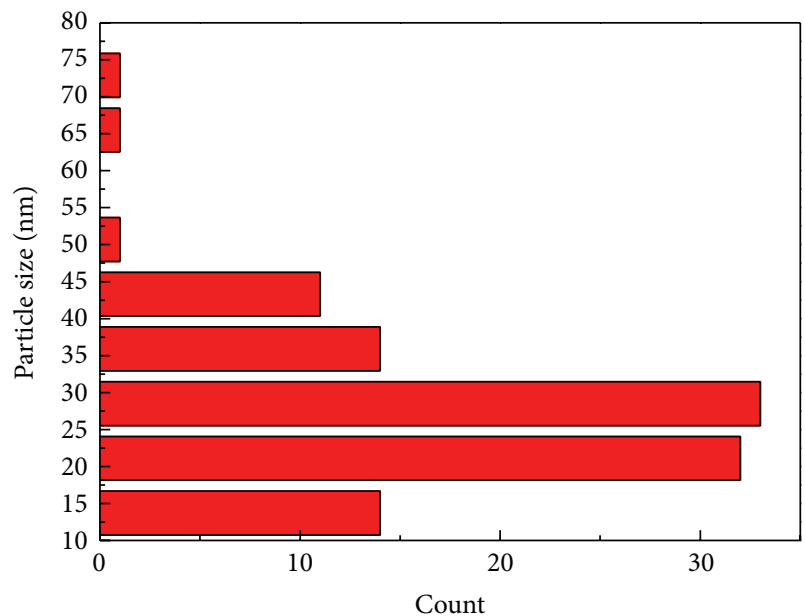

(f)

Figure 5: The particle diameter distribution range of silver nanoparticles with different temperatures: (a) $5^{\circ} \mathrm{C}$; (b) $20^{\circ} \mathrm{C}$; (c) $30^{\circ} \mathrm{C}$; (d) $40^{\circ} \mathrm{C}$; (e) $55^{\circ} \mathrm{C}$; (f) $70^{\circ} \mathrm{C}$ 
concentration of PVP is too high, the thick polymer layers on particles contact mutually producing connection and exacerbating the agglomeration of silver nanoparticles.

3.2. The Influence of Temperature on Silver Nanoparticles. Silver nanoparticles were synthesized at different temperatures, with the uniform mass ratio of $\mathrm{AgNO}_{3}$ to PVP $(1: 4)$. Scanning electron microscopy images are shown in Figure 4, and statistics of silver nanoparticle size are shown in Figure 5. Figure 6 displays the average size of particle synthesized at different temperatures. At $5^{\circ} \mathrm{C}$, nanoparticle agglomeration was remarkable, while the structural regularity and the dispersion of particles were at moderate level, and the average particle size was $38.1 \mathrm{~nm}$. At $20^{\circ} \mathrm{C}$, agglomeration trend of silver nanoparticles weakened; meanwhile the structural regularity degree and the dispersion of particles improved, and the average particle size was $30.3 \mathrm{~nm}$. Few of the AgNPs prepared at $30^{\circ} \mathrm{C}$ agglomerated with each other and the particle size also demonstrated excellent monodispersity. Especially particles within the scope of the average particle size were concentrated, and the average particle size was $22.4 \mathrm{~nm}$. If the reaction temperature rose to $40^{\circ} \mathrm{C}$, agglomeration phenomenon of silver nanoparticles was ordinary; however the structural regularity degree and the dispersion of particles were preferable, and the average particle size was $23.3 \mathrm{~nm}$. When the temperature increased to $55^{\circ} \mathrm{C}$, agglomeration phenomenon of silver nanoparticles was relatively serious, and the structural regularity degree and the dispersion of particles were poor, and the average particle size was $25.4 \mathrm{~nm}$. Finally, when the temperature was $70^{\circ} \mathrm{C}$, agglomeration phenomenon of silver nanoparticles was the worst, and obviously the structural regularity degree and the dispersion of particles were much worse, and average particle size was $28.5 \mathrm{~nm}$.

As the temperature increased, the average particle size of silver nanoparticles also had the tendency of increasing at first and then decreasing, and the increase in amplitude was smaller at high temperature period as we can see in curves of each group's average particle size in Figure 6. Moreover, when the reaction temperature was $30^{\circ} \mathrm{C}$, the particle size demonstrated excellent monodispersity. Besides, the reaction rate was also confirmed to be influenced by the reaction temperature. If the temperature was lower than the critical reaction temperature, it would not react as fully as the reaction at higher temperature. When the temperature increased but is still in the range of low temperature, the surface diffusion made neck formed between particles, leading to the nondensification structure. However if the reaction temperature was exorbitant, nucleation velocity of silver nanoparticles was inferior to the speed of growing up leading to the increase of silver size.

3.3. Tissue Morphology Analysis of Silver Nanoparticles Sintering Paste Sintering to Connect Copper. Silver nanoparticles prepared at $20^{\circ} \mathrm{C}$ with the condition that $\mathrm{AgNO}_{3} / \mathrm{PVP}$ mass ratio was 1:4 were used to sinter, and the morphology of joint is shown in Figure 7. The base metal was tightly bonded together with sintered AgNPs. Moreover, through the

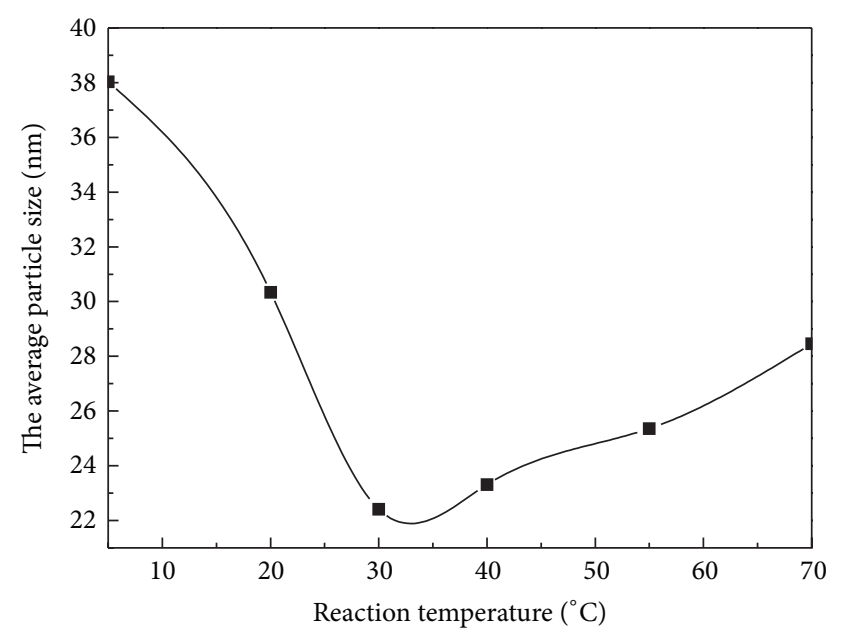

Figure 6: The relation of average silver nanoparticles particle diameter with the temperature.

lining scanning analysis shown in Figure 7(c), the transition gradient of silver and copper content indicated the mutual diffusion, which formed a thin layer of solid solution on the interfaces.

The joint featured porosity characteristics were shown in Figure 7(b). By analysis, we indicated that the emergence of void owed to the silver nondensification diffusion of nanoparticles at low temperature [11]. Densification behavior depends on the sintering temperature. At high temperature, grain boundary and crystal lattice diffusion lead to the formation of densification structure. As temperature rose, surface diffusion consumed a part of energy surrounding the low-temperature zone; as a consequence, the energy was not high enough to drive subsequent densification diffusion at high temperature. In other words, surface diffusion occurs at low temperature and acts the nondensification behavior.

\section{Conclusion}

(1) Large-scale silver nanoparticles with average diameter of $22.4 \mathrm{~nm}$ were successfully prepared by aqueous reduction method. It is indicated that the average diameter of nanoparticles firstly decreased and then increased as the PVP/ $/ \mathrm{ANO}_{3}$ mass ratio or reaction temperature was raised. Nanoparticle size could be well controlled by adjusting both PVP concentration and reaction temperature. It is investigated that optimal $\mathrm{AgNO}_{3} / \mathrm{PVP}$ mass ratio was $1: 4$ and reaction temperature was $30^{\circ} \mathrm{C}$ to minimize the average diameter of nanoparticles with favorable monodispersity, while the agglomeration was remarkably avoided.

(2) Sound low-temperature sintering bonding joints were achieved using the silver nanoparticle paste under the pressure of $10 \mathrm{MPa}$ at $200^{\circ} \mathrm{C}$ for $30 \mathrm{~min}$. Porous sintering morphology as well as limited diffusion at the interface between silver and copper was confirmed. 


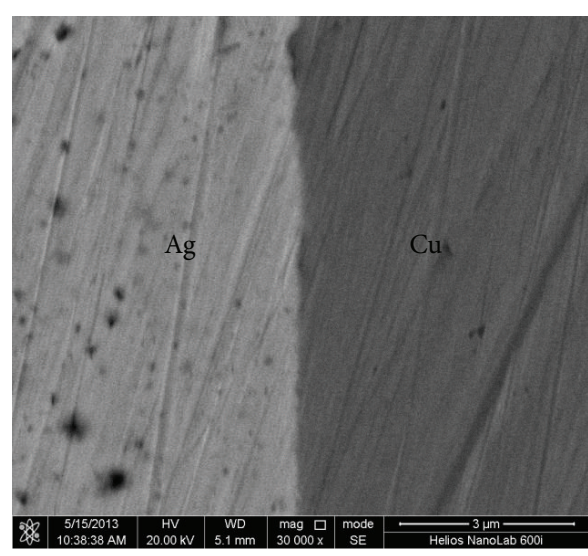

(a)

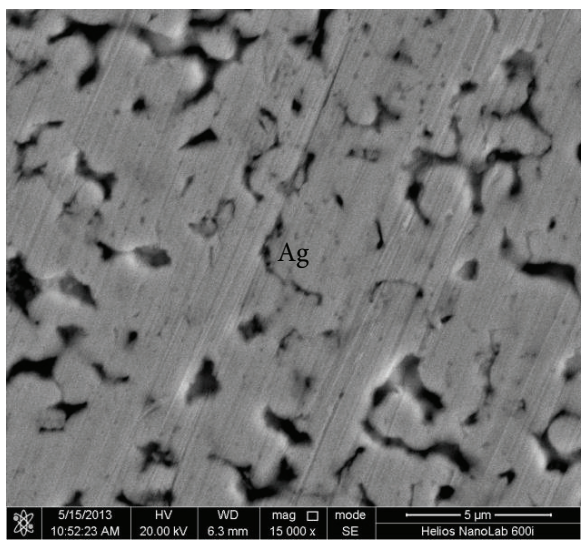

(c)

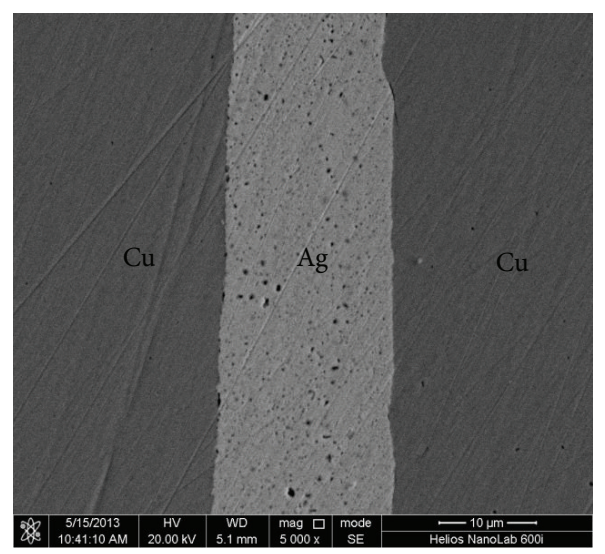

(b)

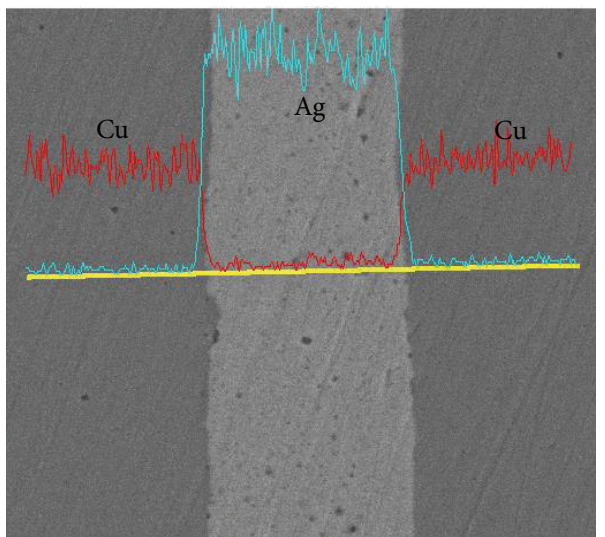

$-\mathrm{Ag}$

(d)

FiguRE 7: The low-temperature sintering bonding using silver nanoparticle paste: (a) the interface of welding joint; (b) the microstructure of joint; (c) the sintered microstructure of silver nanoparticles; (d) the energy spectrogram across the joint.

\section{Conflict of Interests}

The authors declare that they have no conflict of interest regarding the publication of this paper.

\section{Acknowledgment}

The research is partially supported by "National Natural Science Foundation of China (NSFC, Grant nos. 51275135 and 51321061)"”

\section{References}

[1] Y. Li, K.-S. Moon, and C. P. Wong, "Electronics without lead," Science, vol. 308, no. 5727, pp. 1419-1420, 2005.

[2] M. Li, C. Wang, H. Bang, and Y. P. Kim, "Development of a fluxless soldering method by ultrasonic modulated laser," Journal of Materials Processing Technology, vol. 168, no. 2, pp. 303-307, 2005.

[3] X. P. Zhang, L. M. Yin, and C. B. Yu, "Electronic and photonic packaging research on lead-free solder and it's application progress," Journal of Materials Research, vol. 22, no. 1, pp. 1-9, 2008.

[4] Q. L. Ceng, X. L. Gu, X. B. Zhao et al., "The research progress of lead-free solder displacing the one with high temperature and high lead," Journal of Electronic Components and Materials, vol. 27 , no. 8, pp. 16-19, 2008.

[5] M. Scott, "The latest development of nano silver powder in the electronics industry," Regeneration and Utilization of NonFerrous Metal, vol. 12, pp. 36-37, 2004.

[6] Y. Akada, H. Tasum, T. Yamaguchi, A. Hirose, T. Morita, and E. Ide, "Interfacial bonding mech-anism using silvermetalloorganicnanoparticles to bulkmetals andobservation of sintering behavior," Materials Transactions, vol. 49, no. 7, pp. 1537-1545, 2008.

[7] J. Yan, G. S. Zou, J. Li et al., "The sintering properties of nanosilver sintering paste and the research on it's using for copper connecting," Journal of Materials Engineering, no. 10, pp. 5-8, 2010.

[8] K. Qi, Nano-silver sintering paste sintering at low temperature and the research on bonding reliability [Dissertation], Tianjin University Institute of Chemical Industry, Tianjin, China, 2007. 
[9] J. G. Bai, T. G. Lei, J. N. Calata, and G.-Q. Lu, "Control of nanosilver sintering attained through organic binder burnout," Journal of Materials Research, vol. 22, no. 12, pp. 3494-3500, 2007.

[10] J. Jiu, T. Araki, J. Wang et al., "Facile synthesis of very-long silver nanowires for transparent electrodes," Journal of Materials Chemistry A, vol. 2, pp. 6326-6330, 2014.

[11] W. Z. Zhang, X. L. Qiao, and J. G. Chen, "Research progress on the controlled preparation of silver nano-materials," Rare Metal Materials and Engineering, vol. 37, no. 11, pp. 2059-2064, 2008. 

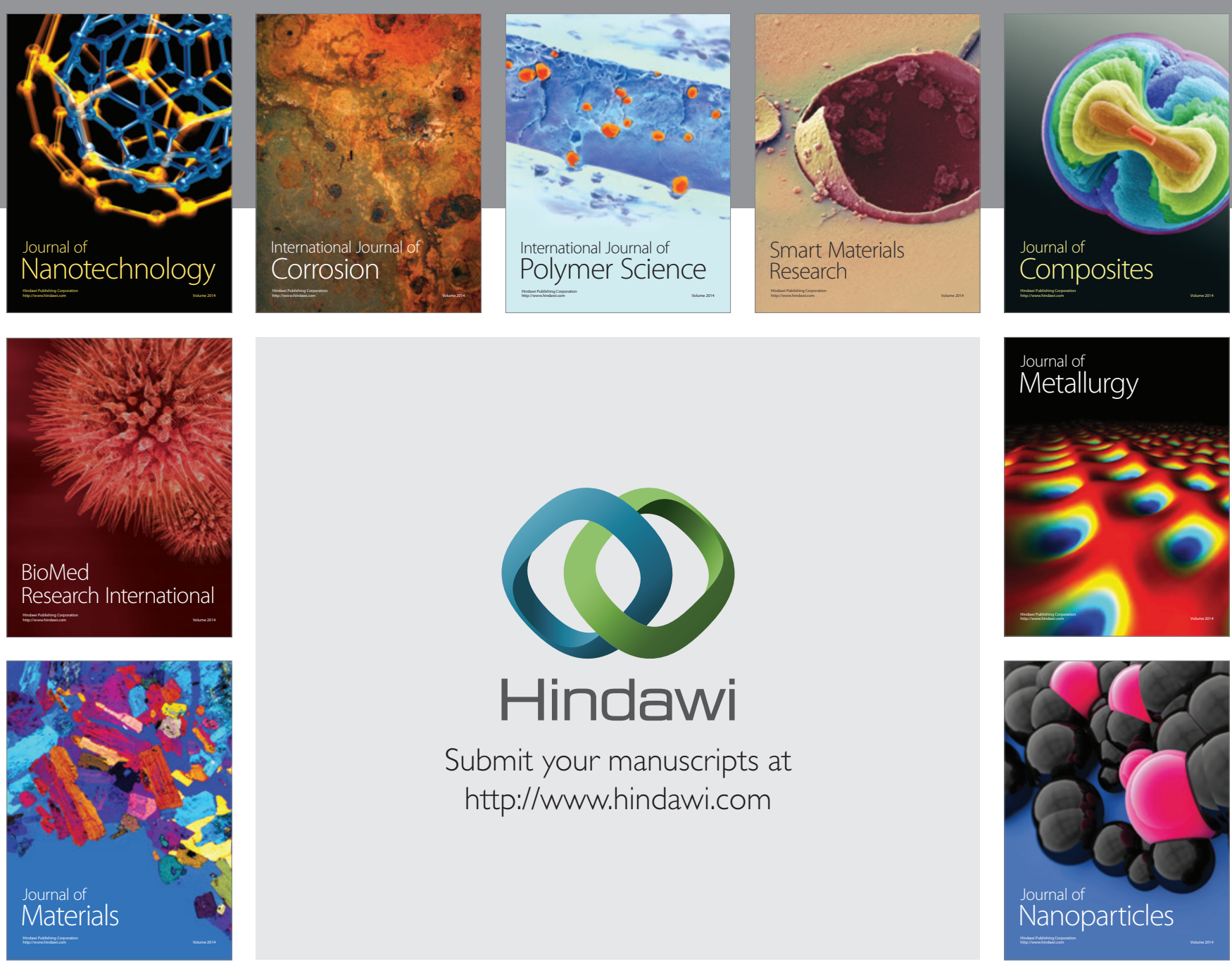

Submit your manuscripts at http://www.hindawi.com
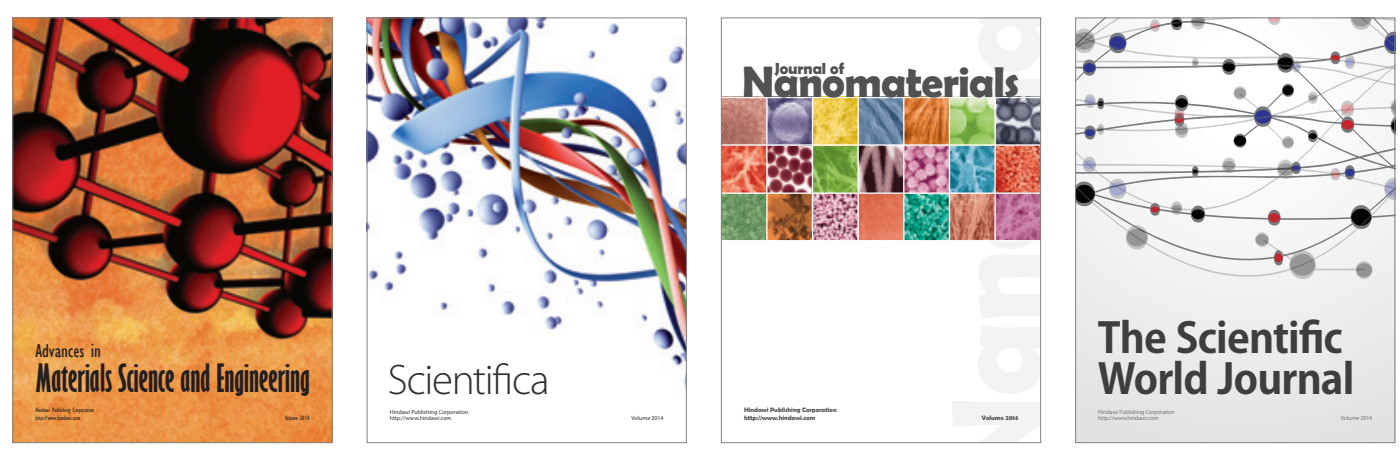

\section{The Scientific World Journal}
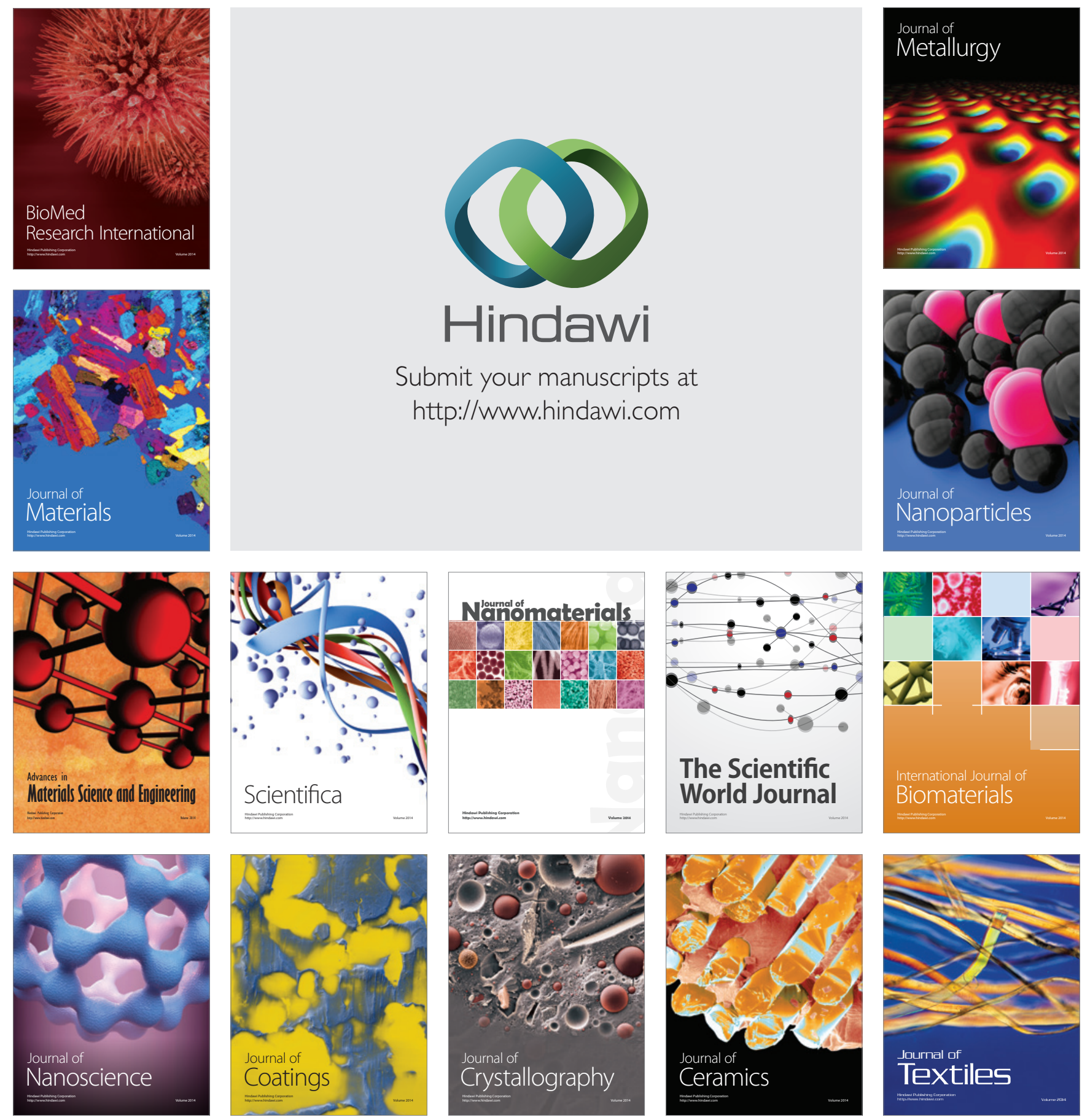